\title{
Active natural-based films for food packaging applications: The combined effect of chitosan and nanocellulose
}

\author{
Sofia M. Costa ${ }^{a}$, Diana P. Ferreira ${ }^{\text {a, } *}$, Pilar Teixeira ${ }^{b}$, Lina F. Ballesteros ${ }^{b}$, José A. Teixeira ${ }^{b}$, Raul Fangueiro ${ }^{a, c}$ \\ a Centre for Textile Science and Technology (2C2T), University of Minho, 4800-058 Guimarães, Portugal \\ b CEB - Centre of Biological Engineering, University of Minho, 4710-057 Braga, Portugal \\ c Department of Mechanical Engineering, University of Minho, 4800-058 Guimarães, Portugal
}

\section{A R T I C L E I N F O}

\section{Article history:}

Received 17 December 2020

Received in revised form 8 February 2021

Accepted 14 February 2021

Available online 22 February 2021

\section{Keywords:}

Chitosan

Cellulose nanocrystals ( $\mathrm{CNC}$ )

Antibacterial

Antifungal

Active food packaging

Food shelf-life

\begin{abstract}
A B S T R A C T
This work aimed to evaluate the potential of chitosan/cellulose nanocrystals (CNC) films to be used as active pads for meat packages to prolong its shelf-life and preserve its properties over time. Several CNC concentrations (5, 10,25 , and $50 \mathrm{wt} \%$ ) were tested and the films were produced by solvent casting. The developed samples were characterized by ATR-FTIR, TGA, FESEM, and XRD. The transparency, antimicrobial, barrier and mechanical properties were also assessed. Finally, the films' ability to prolong food shelf-life was studied in real conditions using chicken meat.

CNC incorporation improved the thermal stability and the oxygen barrier while the water vapor permeability was maintained. An enhancement of mechanical properties was also observed by the increase in tensile strength and Young's modulus in chitosan/CNC films. These films demonstrated bactericidal effect against Gram-positive and Gram-negative bacteria and fungicidal activity against Candida albicans. Lastly, chitosan-based films decreased the growth of Pseudomonas and Enterobacteriaceae bacteria in meat during the first days of storage compared to commercial membranes, while chitosan/CNC films reduced the total volatile basic nitrogen (TVB-N), indicating their efficiency in retarding meat's spoilage under refrigeration conditions.
\end{abstract}

This work highlights the great potential of natural-based films to act as green alternatives for food preservation. (c) 2021 Elsevier B.V. All rights reserved.

\section{Introduction}

Nowadays, one of the main challenges in the food industry is the development of new environmentally friendly active food packages able to prolong the food shelf-life, while ensuring its quality and safety [1]. The growing consumer demand for fresh, safe and healthy food products without containing synthetic additives or preservatives increases the need to explore novel, effective and innovative food preservation technologies able to prolong its shelf-life, which makes the food packaging sector an emergent trend area with a great business potential [2]. Parallelly, with the increase of environmental awareness, the search for green alternatives able to minimize the negative ecological impact of conventional materials extracted from nonrenewable resources is increasing tremendously. Consequently, biodegradable polymers arise as a promising option to replace the petroleum-based polymers due to their easy decomposition under suitable environmental conditions [3,4]. Furthermore, the

\footnotetext{
* Corresponding author.

E-mail addresses: sofiamcosta@det.uminho.pt (S.M. Costa), diana.ferreira@det.uminho.pt (D.P. Ferreira), pilar@deb.uminho.pt (P. Teixeira), jateixeira@deb.uminho.pt (J.A. Teixeira), rfangueiro@dem.uminho.pt (R. Fangueiro).
}

use of biodegradable polymers will contribute to the reduction of packaging waste, derived from the extensive use of synthetic and non-biodegradable polymers, which has become a significant part of the total waste $[4,5]$.

Over the last few years, chitosan has emerged as an attractive material for several applications due to its excellent characteristics. Chitosan is a polysaccharide derived from the deacetylation of chitin, which can be obtained from marine waste sources, namely from crustaceans' shells (shrimp, oysters, crabs, and lobsters). Besides its natural origin, this polymer presents several other interesting properties, such as biodegradability, non-toxicity, biocompatibility, low-cost, and excellent film-forming capacity [6-9]. The obtention of chitosan from marine wastes allows the valorization of seafood waste to the manufacture of value-added products, in line with the concept of circular economy [10,11].

In the food packaging industry, minimizing the microorganisms' development and spread is crucial to prevent food deterioration, ensuring its safety. In fact, chitosan displays intrinsic antimicrobial activity against a wide range of bacteria and fungi due to its polycationic nature. It also exhibits antioxidant, anti-inflammatory, and anticancer activities, demonstrating the great applicability of this biopolymer not only for food protection and packaging but also for other fields, like biomedicine 
and agriculture [3,12-15]. Nevertheless, natural-based polymers present some limitations, such as poor mechanical and barrier properties, which can negatively affect the food shelf-life parameters and limit the use of this polymer on a large-scale. Several approaches can be adopted to overcome these drawbacks, including the combination of chitosan with nanofillers [16,17].

In recent years, cellulose nanocrystals (CNC) have arisen as an innovative nanomaterial to act as a reinforcing agent. CNC are commonly obtained by acid hydrolysis of cellulose, the most abundant natural polymer, where the amorphous regions are removed while the crystalline ones are maintained. Due to their outstanding characteristics, such as nanometric size, large surface area, high strength, non-toxicity, high crystallinity, and biodegradability, these nanocrystals are attracting growing interest from the scientific community [18-20]. The CNC incorporation into biopolymeric matrices allows the production of high-performance materials, without impairing their biodegradability while enhancing their mechanical resistance and barrier properties [19-23]. Despite some studies reporting the combination of chitosan with CNC for food packaging applications [18,19,23-26], to the best of authors' knowledge, there is still to address the impact of this system on food shelf-life through the quantification of total volatile basic nitrogen (TVB-N), which represents a food freshness indicator, using a real food system under refrigerated conditions.

Therefore, the aim of this research work was to evaluate the potential of an active natural-based and biodegradable pad containing chitosan and CNC to replace the passive pads already existent on the common meat packages. Several CNC concentrations were incorporated into chitosan solutions and the films were produced by the solvent casting technique. All the developed samples were characterized by Attenuated Total Reflectance-Fourier Transform Infrared Spectroscopy (ATR-FTIR), Thermogravimetric analysis (TGA), Field Emission Scanning Electron Microscopy (FESEM), and X-Ray Diffraction (XRD). The functional properties were also evaluated, including the transparency, the antibacterial and antifungal activities, the water vapor and oxygen permeabilities and the mechanical properties. Finally, the ability of the samples to delay food spoilage, and consequently, to increase its shelflife, under refrigeration storage conditions was performed using a real food model system through the evaluation of exudate absorption capacity of the films, the detection and enumeration of different bacteria and TVB-N quantification in chicken meat.

\section{Materials and methods}

\subsection{Materials}

Chitosan powder with a molecular weight of 100,000-300,000 g/ mol was supplied by ACROS Organics. CNC powder was purchased from CelluForce (spray-dried powder form, cellulose nanocrystals with diameters $\sim 75 \mathrm{~nm}$, polydispersity index (PDI) $=0.181$, CelluForce NCC $®)$. Glacial acetic acid $99-100 \%$ a.r. and glycerol $99 \%$ were obtained from NORMAX and Scharlau, respectively.

\subsection{Chitosan/CNC films preparation}

Firstly, 2\% ( $w / v)$ of chitosan solution was prepared by dissolving chitosan powder in an aqueous solution of $1 \%(\mathrm{v} / \mathrm{v})$ of acetic acid under vigorous stirring for $1 \mathrm{~h}$. After that, several CNC concentrations were incorporated $(5,10,25$, and $50 \mathrm{wt} \%$ in relation to chitosan weight). These solutions were left under constant stirring for $24 \mathrm{~h}$ and homogenized. Subsequently, $1 \%(w / v)$ of glycerol was added and the solutions were sonicated in an ultrasonic bath for $1 \mathrm{~h}$. Finally, the solutions were cast on Petri dishes and also in special molds designed for the proper application as pads for meat packages. After casting, the films were dried at $35^{\circ} \mathrm{C}$ for $48 \mathrm{~h}$.

\subsection{Samples characterization}

2.3.1. Attenuated total reflectance-fourier transform infrared spectroscopy (ATR-FTIR)

ATR-FTIR analysis was carried out in an IRAffinity-1S, SHIMADZU equipment (Kyoto, Japan). For each sample, a total of 45 scans with a resolution of $4 \mathrm{~cm}^{-1}$ was obtained in transmittance mode using a diamond ATR crystal cell. The measurements were recorded in the range of 400 and $4000 \mathrm{~cm}^{-1}$.

\subsubsection{Thermogravimetric analysis (TGA)}

TGA analysis was performed in an STA 700 SCANSCI. The samples were heated from $30{ }^{\circ} \mathrm{C}$ to $600{ }^{\circ} \mathrm{C}$ with a heating rate of $10{ }^{\circ} \mathrm{C} / \mathrm{min}$ under nitrogen atmosphere.

\subsubsection{Field emission scanning electron microscopy (FESEM)}

The surface and cross-section morphology of the films were visualized by FESEM using a NOVA 200 Nano SEM from FEI Company (Hillsboro, OR, USA). Before the experiment, the samples were coated with a very thin film $(20 \mathrm{~nm})$ of Gold ( $\mathrm{Au}$ )-Palladium (Pd), using a highresolution sputter coater, 208 HR Cressington Company (Watford, UK), coupled to an MTM-20 Cressington High-Resolution Thickness Controller. Secondary electron images, i.e., topographic images, were obtained at an acceleration voltage of $5 \mathrm{kV}$.

\subsubsection{X-ray diffraction (XRD)}

The XRD analysis was carried out in a Bruker D8 Discover diffractometer, using $\mathrm{Cu}-\mathrm{K}_{\beta}$ radiation at a voltage of $40 \mathrm{kV}$ and a current of $40 \mathrm{~mA}$. Data were collected for $2 \theta$ values ranging from $5^{\circ}$ to $45^{\circ}$.

\subsection{Functional properties evaluation}

\subsubsection{Thickness and transparency}

The samples' thickness was measured using a digital caliper. Five different randomly positions of each film were recorded and the average thickness was determined. The transparency values of the films were determined by measuring the samples' light transmittance at $600 \mathrm{~nm}$, using a Spectrophotometer UV-2600 (Schimadzu) with the ISR 2600 Plus detector, and calculated according to the eq. 1 [27].

$T V=-\log T_{600} / x$

where TV is the transparency value, $\mathrm{T}_{600}$ is the fractional transmittance at $600 \mathrm{~nm}$ and $x$ is the film thickness $(\mathrm{mm})$.

\subsubsection{Antimicrobial activity}

Antimicrobial activity was assessed using the immersion method. The microorganisms assayed were the Gram-positive bacteria Staphylococcus aureus (ATCC 6538), the Gram-negative bacteria Escherichia coli (ATCC 434), and the yeast Candida albicans SC5314. Briefly, inocula of E. coli and S. aureus were prepared in $20.0 \pm 0.1 \mathrm{~mL}$ of TSB (Tryptic Soy Broth, Merck) and an inoculum of $C$. albicans was prepared in $20.0 \pm 0.1 \mathrm{~mL}$ of SDB (Sabouraud dextrose broth, Merck) and incubated for a period of 18 to $24 \mathrm{~h}$ at $37 \pm 1{ }^{\circ} \mathrm{C}$ under agitation ( $\left.120 \mathrm{rpm}\right)$. Then, microbial concentrations were adjusted to $3 \times 10^{8}$ cells $/ \mathrm{mL}$ via absorbance readings and based on a corresponding calibration curve. An aliquot of each suspension ( $400 \mu \mathrm{L}$ ) was added to $20 \mathrm{~mL}$ of TSB for E. coli and S. aureus and to $20 \mathrm{~mL}$ of SDB for C. albicans, and incubated for $3.0 \mathrm{~h}$ at $37 \pm 1{ }^{\circ} \mathrm{C}$. The microbial concentration was again measured and $3 \times 10^{5}$ cells $/ \mathrm{mL}$ were obtained using a 20 -fold dilution of the respective medium (in distilled water). Two milliliters of this inoculum was then added to each sample in conical tubes. Samples were incubated for $24 \mathrm{~h}$ at $37 \pm 1{ }^{\circ} \mathrm{C}$, under agitation (120 rpm). After this period, the tubes were subjected to vigorous agitation, samples were collected and the number of CFU determined by plating serial dilutions. All assays were performed in triplicate and repeated in three independent assays. 
The value of antimicrobial activity was calculated according to Eq. (2), where R - Value of antimicrobial activity, I - Mean number of viable cells of bacteria in the inoculum after $24 \mathrm{~h}$ and $\mathrm{T}$ - Mean number of viable bacteria cells in the antimicrobial test piece after $24 \mathrm{~h}$.

$\mathrm{R}=[\log (\mathrm{I} / \mathrm{T})]$

\subsubsection{Barrier properties}

Oxygen permeability $\left(\mathrm{O}_{2} \mathrm{P}\right)$ was carried out according to the ISO 15105-2:2003 Standard test, following the methodology reported by Fernandes et al. [28]. Briefly, the films were sealed between two vertical chambers, having each one-two channels (for the input and output of gasses). The top chamber was supplied with a controlled oxygen flow rate of $25 \mathrm{~mL} / \mathrm{min}$ in order to keep a constant pressure in that compartment. The bottom chamber was purged with nitrogen, at a controlled flux rate of $5 \mathrm{~mL} / \mathrm{min}$, acting as the carrier gas for the oxygen. The measurements of oxygen concentration were carried out by collecting $500 \mu \mathrm{L}$ of the sample from the nitrogen flow leaving the bottom chamber flow with a suitable syringe for gas chromatography (Hamilton, Switzerland). Subsequently, the sample gas was injected into a gas chromatograph (Bruker Scion 456, Canada), equipped with a thermal conductivity detector (TCD) at $130{ }^{\circ} \mathrm{C}$, a Molsieve column, and argon (30 $\mathrm{mL} / \mathrm{min}$ ) as the carrier gas. A mixture containing $10 \% \mathrm{CO}_{2}, 20 \% \mathrm{O}_{2}$, and $70 \% \mathrm{~N}_{2}$ was used as the standard sample for calibration. The pressure in the cells was measured to ensure that $1 \mathrm{~atm}$ pressure exerted in both chambers. As the oxygen was carried continuously by the nitrogen flow, it was considered that $\mathrm{O}_{2}$ partial pressure in the lower compartment is null, therefore $\Delta \mathrm{P}$ is equal to $1 \mathrm{~atm}$. The $\mathrm{O}_{2} \mathrm{P}$ was determined by using eq. (3), where $F$ is the registered flux at the output channel of the below chamber $(\mathrm{mL} / \mathrm{min}), \mathrm{O}_{2}$ represents the measured oxygen transmission rate through the film (\%), $E$ is the mean sample thickness $(\mathrm{m}), A$ represents the film area $\left(\mathrm{m}^{2}\right)$, and $P$ is the atmospheric pressure at room temperature ( $\mathrm{Pa}$ ). The $\mathrm{O}_{2} \mathrm{P}$ was expressed as $\mathrm{m}^{3} / \mathrm{s} \mathrm{m} \mathrm{Pa}$ and three replicates were obtained for each film.

$\mathrm{PO}_{2}=\mathrm{F} \times \mathrm{O}_{2} \times E / A \times P$

Water vapor permeability (WVP) was performed gravimetrically according to ASTM E96-95 Standard test methods as described by Ballesteros et al. [29]. The films were sealed on the top of permeation cells containing $60 \mathrm{~mL}$ of distilled water (100\% relative humidity ( $\mathrm{RH})$ and vapor pressure at $20^{\circ} \mathrm{C}$ ), and then, placed into a desiccator with silica gel $\left(0 \% \mathrm{RH}\right.$ and water vapor pressure at $\left.20{ }^{\circ} \mathrm{C}\right)$. The cells were weighted at $2 \mathrm{~h}$ intervals for monitoring the weight loss during $10 \mathrm{~h}$. Steady-state and uniform water pressure conditions were assumed by keeping the air circulation constant outside the test cell by using a fan inside the desiccator. WVP was determined by using the Eq. (4), where WVTR is the measured water vapor transmission rate through a sample, calculated by dividing the slope of the linear regression of weight loss versus time by the film area $(\mathrm{g} / \mathrm{s} \mathrm{m}), L$ is the mean sample thickness $(\mathrm{m})$, and $\Delta P$ is the partial water vapor pressure difference (Pa) across the two sides of the sample. WVP was expressed as $\mathrm{g} / \mathrm{m} \mathrm{s}$ $\mathrm{Pa}$ and three replicates were made for each film.

$W V P=W V T R \cdot L / \Delta P$

\subsubsection{Mechanical properties}

To evaluate the effect of CNC incorporation into the chitosan films, tensile tests were performed. These tests were made using a Hounsfield Tinius Olsen, model H100KPS equipment with a load cell of $250 \mathrm{~N}$. The samples were cut in strips with $10 \mathrm{~mm}$ of width and $90 \mathrm{~mm}$ of length, accordingly with Ferreira et al. [30]. The initial grip separation was set at $50 \mathrm{~mm}$ and the crosshead speed at $30 \mathrm{~mm} / \mathrm{min}$. The tensile strength, elongation at break and Young's modulus were calculated from the stress-strain curves. Five replicates of each sample were tested.

\subsection{Shelf-life tests}

\subsubsection{Sample preparation and storage}

In order to evaluate the potential of the films to act as absorbent and active membranes/pads for food packaging, shelf-life tests were performed using chicken meat. In this case, the chitosan-based films (Fig. 1A) were used to replace the commercial absorbent and passive membranes commonly found in meat trays, as can be observed in Fig. 1B.

Commercial membranes were also utilized in this study to compare its performance with the developed samples. Briefly, fresh chicken breasts were purchased in a local butcher and transported under refrigeration conditions to the laboratory on the same day of packaging. In each tray, $200 \mathrm{~g}$ of chicken breast were placed on the samples. The trays were closed in standard atmospheric conditions (aerobic conditions) at $4{ }^{\circ} \mathrm{C}$ for 14 days.

\subsubsection{Exudate absorption capacity}

The exudate absorption capacity of chitosan, chitosan/CNC films and commercial membranes was tested by a methodology based on Edana recommended test. Discs of samples ( $7 \mathrm{~cm}$ of diameter) were weighted, immersed for $2 \mathrm{~min}$ in $0.9 \% \mathrm{NaCl}$ solution ( $\mathrm{pH}=5$ ), submitted to $80 \mathrm{~g}$ of pressure and weighted again. The result was given in percentage relative to the initial mass.

\subsubsection{Microbiological analysis}

Microbiological analysis was performed using standard methods (International Organization for Standardization and Portuguese standards). The following microbiological parameters were considered: enumeration of Enterobacteriaceae - ISO 21528-2:2017, enumeration of Pseudomonas spp. - ISO 13720:2010, enumeration of Listeria monocytogenes - ISO 11290-2:2017, enumeration of Campylobacter
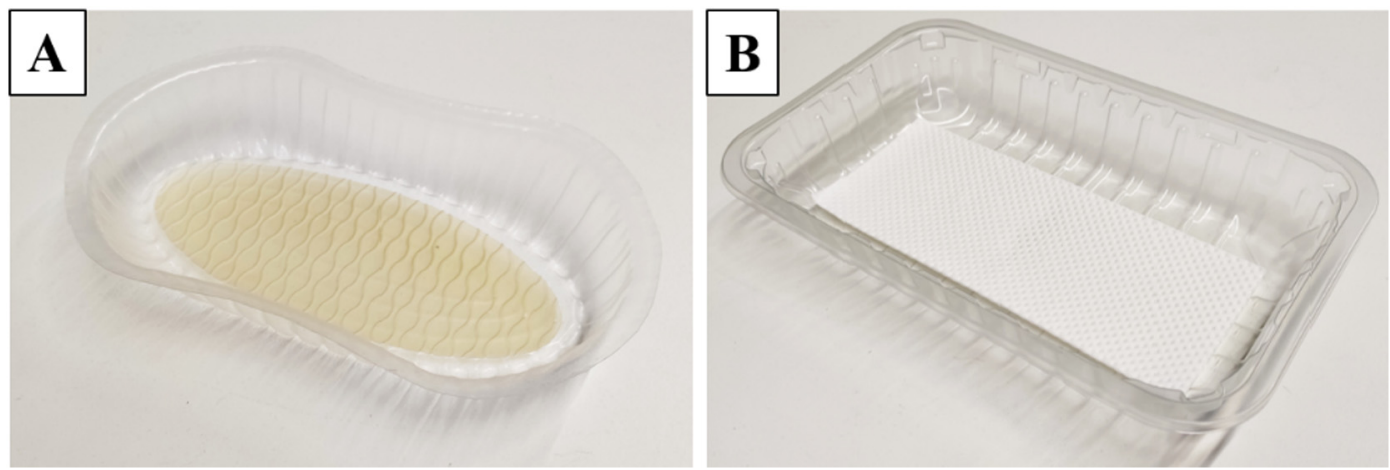

Fig. 1. Meat trays covered with the developed films (A) and the commercial membranes (B). 
spp. - ISO 10272-2:2017, detection of Campylobacter spp. based in the ISO 10272-1:2017. Initial suspension of the samples (25 g) were enriched in $225 \mathrm{~mL}$ of selective Bolton broth with $5 \%$ sterile lyzed horse blood and incubated for $18 \mathrm{~h}$ at $42{ }^{\circ} \mathrm{C}$ in microaerophilic atmosphere. The presence of Salmonella spp. was performed according to Vidas Biomérieux method, with the positive results confirmed following the ISO 6579-1:2017. Sample of $25 \mathrm{~g}$ was taken aseptically from each packaging of poultry meat, transferred aseptically to a stomacher bag containing $225 \mathrm{~mL}$ of sterile buffered peptone water and homogenized using a stomacher for $30 \mathrm{~s}$ at room temperature. Appropriate decimal dilutions were prepared in sterile Ringer's solution for the microbial enumeration parameters.

\subsubsection{Chemical analysis}

The TVB-N content, which is an indicator of meat's freshness, was determined by the Conway micro-diffusion method according to the standard NP-1848:1987. In this way, $50 \mathrm{~g}$ of meat sample was homogenized for $2 \mathrm{~min}$ with $100 \mathrm{~mL}$ of trichloroacetic acid $0.5 \%(w / v)$ solution, and $1 \mathrm{~mL}$ of this filtrate was used. The volatile bases were released from the filtrate, by alkalization with sodium carbonate during $90 \mathrm{~min}$ at $40{ }^{\circ} \mathrm{C}$ in an oven, collected in a boric acid $1 \%(\mathrm{w} / \mathrm{v})$ solution, and titrated with hydrochloric acid $(\mathrm{HCl}) 0.1 \mathrm{~mol} / \mathrm{L}$ standard solution. The TVB-N content was evaluated at different storage days $(0,2,5,7,9$, and 14 day). The results were expressed as $\mathrm{mg} \mathrm{N} / 100 \mathrm{~g}$ chicken meat.

\subsection{Statistical analysis}

Statistical analysis was performed using a GraphPad Prism (version 6.0). One-way analysis of variance (ANOVA) and Tukey's multiple comparison tests were performed to evaluate the significant differences between the samples. Data are presented by mean \pm standard deviation (SD). Statistical significance was considered if $p<0.05$.

\section{Results and discussion}

\subsection{Samples characterization}

\subsubsection{Chemical analysis}

ATR-FTIR analysis was performed to evaluate the structural interaction between chitosan and CNC. Fig. 2 shows the spectra of CNC powder, chitosan films and chitosan containing different CNC amounts.

The ATR-FTIR spectrum of CNC powder showed several CNC typical bands, namely the bands located in the region of $3200-3400 \mathrm{~cm}^{-1}$

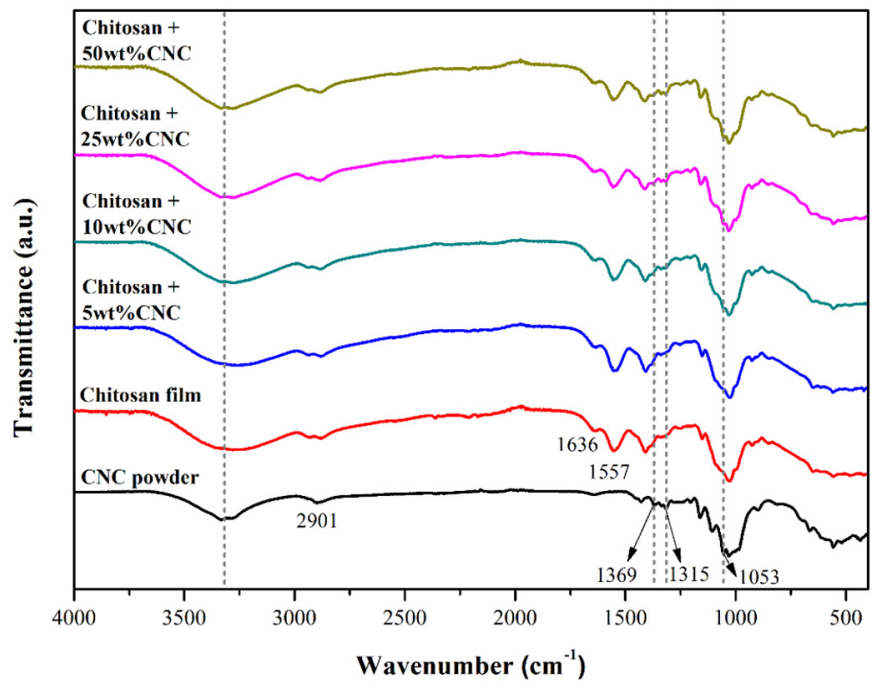

Fig. 2. ATR-FTIR spectra of CNC powder and chitosan films incorporated with different CNC concentrations $(0,5,10,25$ and $50 \mathrm{wt} \%)$. and the one at $2901 \mathrm{~cm}^{-1}$, which correspond to stretching vibrations of the $\mathrm{O}-\mathrm{H}$ groups of cellulose and the $\mathrm{C}-\mathrm{H}$ stretching, respectively [31-34]. The band at $1645 \mathrm{~cm}^{-1}$ is attributed to $\mathrm{O}-\mathrm{H}$ bending of the adsorbed water, the band at $1429 \mathrm{~cm}^{-1}$ is from symmetric bending of $\mathrm{CH}_{2}$ and the band at $1369 \mathrm{~cm}^{-1}$ corresponds to $\mathrm{CH}$ deformation vibration [31-33]. Moreover, the bands at 1335 and $1315 \mathrm{~cm}^{-1}$ arise from the rocking of $\mathrm{OH}$ and the bending vibrations of the $\mathrm{C}-\mathrm{H}$ and $\mathrm{C}-\mathrm{O}$ groups of the rings in polysaccharides, respectively [31,35]. The bands observed in the range $1030-1161 \mathrm{~cm}^{-1}$ correspond to C-O stretching and $\mathrm{C}-\mathrm{H}$ rocking vibrations of the pyranose ring [31]. Finally, the bands at 897 and $557 \mathrm{~cm}^{-1}$ are from $\beta$-glycosidic linkages in cellulose structure and $\mathrm{O}-\mathrm{H}$ out of plane bending vibrations, respectively $[18,23,35]$.

Chitosan films spectrum displayed the main characteristic bands of this biopolymer including a broad band located at $3279 \mathrm{~cm}^{-1}$, which corresponds to $\mathrm{O}-\mathrm{H}$ and $\mathrm{N}-\mathrm{H}$ stretching vibrations, and a band around $2960-2870 \mathrm{~cm}^{-1}$ that is from symmetric and asymmetric $\mathrm{C}-\mathrm{H}$ vibrations [6,13,33]. Moreover, the bands at 1636 and $1557 \mathrm{~cm}^{-1}$ are attributed to $\mathrm{C}=\mathrm{O}$ stretching (amide $\mathrm{I}$ ) and $\mathrm{N}-\mathrm{H}$ bending (amide II), respectively [6,33,34,36,37]. Finally, the bands located at $1250,1152,1028$ and $926 \mathrm{~cm}^{-1}$ correspond to saccharide structure, where the one at $1250 \mathrm{~cm}^{-1}$ is from $\mathrm{C}-\mathrm{N}$ stretching, $1152 \mathrm{~cm}^{-1}$ is from symmetric stretching of $\mathrm{C}-\mathrm{O}-\mathrm{C}$ bond and $1028 \mathrm{~cm}^{-1}$ is from $\mathrm{C}-\mathrm{O}$ stretching vibrations [6,33].

Regarding the ATR-FTIR spectra of chitosan/CNC films, it was possible to observe the appearance of new bands related to CNC, namely the ones at 1369,1315 , and $1053 \mathrm{~cm}^{-1}$, as well as the increase in intensity of several other bands, confirming the successfully CNC incorporation into chitosan matrix. These results became more visible with $10 \mathrm{wt} \%$ of CNC and are more pronounced accordingly with CNC amount. Finally, the band in the region of $3200-3400 \mathrm{~cm}^{-1}$ became sharper and with higher intensity with the increase of nanofillers concentration, suggesting the formation of hydrogen bonds between chitosan and CNC molecules, as demonstrated by several authors [18,38].

\subsubsection{Thermal analysis}

TGA was performed to evaluate the thermal stability of the samples. The TG and its first order derivate (DTG) curves obtained are represented in Fig. 3.

The thermal degradation of $\mathrm{CNC}$ powder can be divided into three main mass loss steps. The first one occurs at $30-103{ }^{\circ} \mathrm{C}$ with a weight loss of around 3\%, which corresponds to the evaporation of water molecules. From $250{ }^{\circ} \mathrm{C}$ to $330{ }^{\circ} \mathrm{C}$ the major weight loss was observed, with a maximum degradation peak at $305{ }^{\circ} \mathrm{C}$, which is due to depolymerization, dehydration, and decomposition of glycosyl units from cellulose. Finally, the third step around $330-400{ }^{\circ} \mathrm{C}$ is probably related to residues from the CNC extraction process with sulfuric acid $[33,39,40]$. The degradation profile of chitosan powder exhibited two main mass loss stages, namely at $30-120^{\circ} \mathrm{C}$ and $200-400{ }^{\circ} \mathrm{C}$, which are attributed to the loss of moisture and the depolymerization of chitosan chains, respectively [33]. The maximum degradation peak of chitosan powder was detected at $302{ }^{\circ} \mathrm{C}$.

In chitosan films, three major degradation stages can be observed. The first one was recorded between 30 and $103^{\circ} \mathrm{C}$, which is attributed to the evaporation of water and residual acetic acid. The second stage at $103-230^{\circ} \mathrm{C}$ is related to glycerol degradation. Finally, the main degradation stage occured at $230-400^{\circ} \mathrm{C}$, with a weight loss of around $30 \%$, which corresponds to chitosan decomposition and depolymerization $[13,23,37]$. The CNC incorporation led to the appearance of a new peak in the region around $320 / 330-400{ }^{\circ} \mathrm{C}$ associated with the second loss stage of CNC, which becomes more pronounced with the increase of CNC content, confirming the presence of these nanofillers into the polymeric matrix [41]. The main peak related to CNC degradation overlap with the same temperature range of chitosan degradation, as demonstrated in Fig. 3B. Therefore, only one peak was observed in the region of $230-320{ }^{\circ} \mathrm{C}$, which is attributed to both chitosan and $\mathrm{CNC}$ 

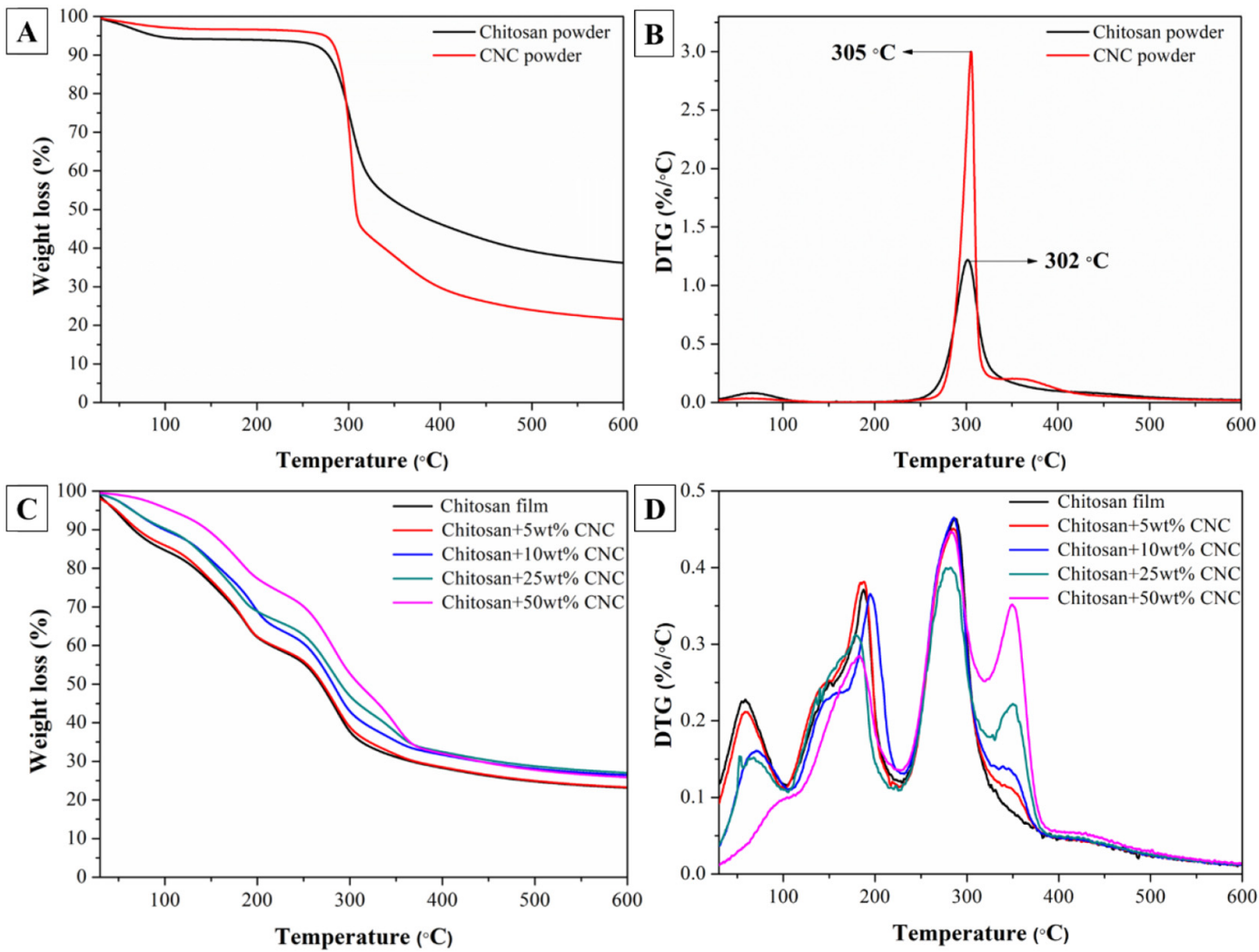

Fig. 3. TG and DTG curves of chitosan and CNC powders (A and B) and chitosan films incorporated with different CNC concentrations ( $0,5,10,25$ and 50 wt\%) (C and D).

degradation. Chitosan/CNC films showed slightly higher TG degradation curves than chitosan films without CNC, mainly until $400{ }^{\circ} \mathrm{C}$ (Fig. 3C), which indicates that the weight loss of chitosan/CNC samples was lower than control chitosan films [23]. In fact, chitosan films exhibited a total weight loss of $72 \%$ until $400{ }^{\circ} \mathrm{C}$. On the other hand, chitosan with 50 wt\% of CNC films demonstrated smaller weight loss (68\%), in the same temperature range. Hence, these results suggest that chitosan/CNC films presented overall improved thermal stability [19].

\subsubsection{Morphology analysis}

In order to evaluate the morphology of the chitosan and chitosan/ CNC films, FESEM analysis was performed. The FESEM images of the
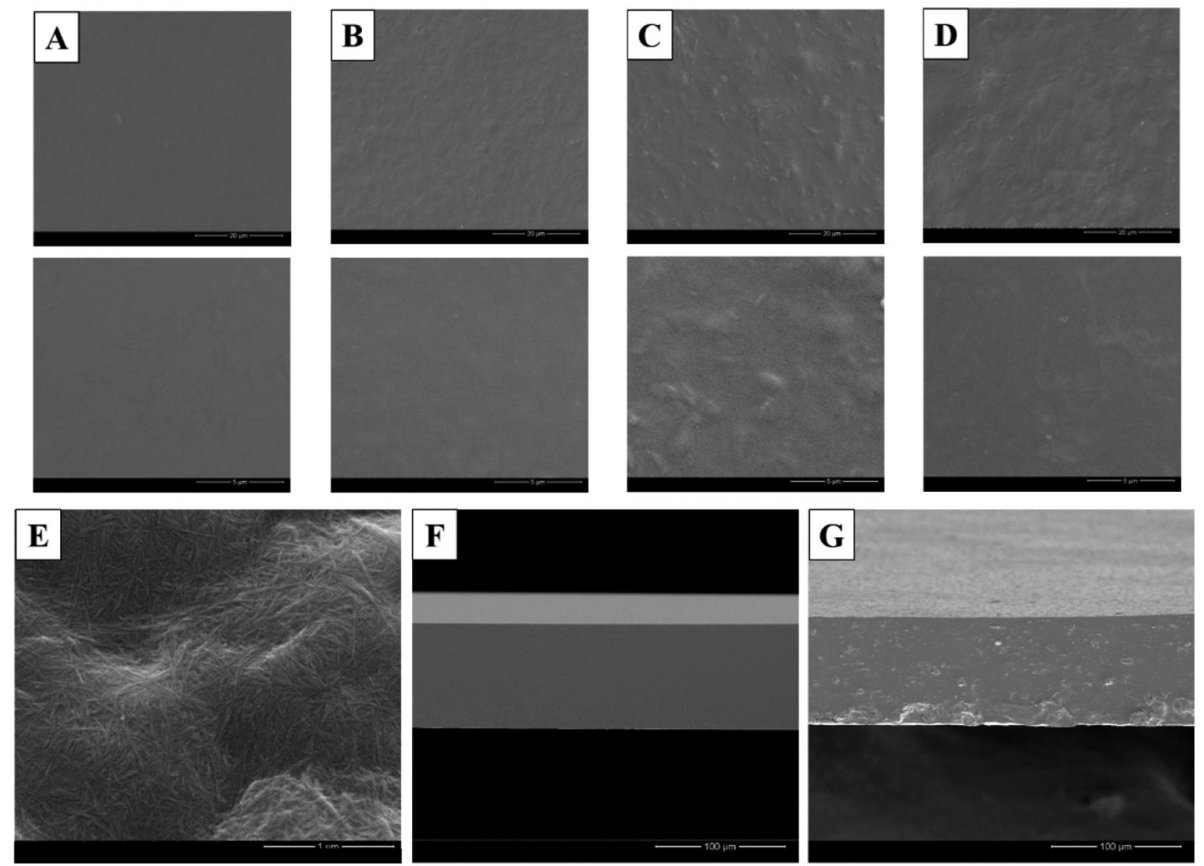

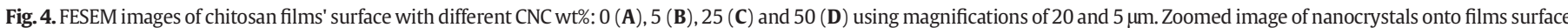
(E) at $1 \mu \mathrm{m}$. Cross-section images of chitosan (F) and chitosan/CNC (G) films at $100 \mu \mathrm{m}$. 
samples' surface and cross-section morphology are shown in Fig. 4 (as example).

As demonstrated in Fig. 4A and F, the morphology of the surface and cross-section of chitosan films is very homogeneous and smooth. On the other hand, the CNC incorporation into chitosan films led to the appearance of a rougher surface and this effect was more pronounced with the increase of CNC amount. Moreover, the nanocrystals seem to be uniformly distributed into the chitosan matrix, without any notable aggregation clusters (Fig. 4E). Fig. 4G also demonstrated that $\mathrm{CNC}$ are embedded throughout the chitosan film, suggesting a strong adhesion between the nanofillers and the polymeric matrix $[18,23,33]$.

\subsubsection{Crystalline structure}

The diffractograms of CNC powder, chitosan and some samples of chitosan/CNC films are presented in Fig. 5.

The XRD pattern of CNC powder revealed the characteristic peaks of crystalline cellulose I at $2 \theta=15.1^{\circ}, 16.5^{\circ}, 22.5^{\circ}$ and a weak peak at $34.4^{\circ}$. These peaks correspond to the ( $\left.1 \overline{1} 0\right),(110),(200)$ and $(00$ 4) crystallographic planes, respectively, which are in agreement with different studies [19,34,35,40,42]. Chitosan films exhibited four diffraction peaks at $2 \theta=8.12^{\circ}, 11.4^{\circ}, 18.0^{\circ}$, and a broad peak around $22.5^{\circ}$ due to its semi-crystalline nature $[9,19]$. Regarding chitosan/CNC films, both chitosan and CNC specific peaks were observed, indicating the efficient incorporation and preservation of CNC crystalline structure into polymeric films [18,22]. Moreover, the increase in the intensity of CNC peaks as well as a decrease in the intensity of chitosan peaks was evident with the gradual increase of CNC concentration.

\subsection{Functional properties evaluation}

\subsubsection{Thickness and transparency}

Transparency represents an important factor for food packaging applications since influences the consumer's choice. Higher transparency

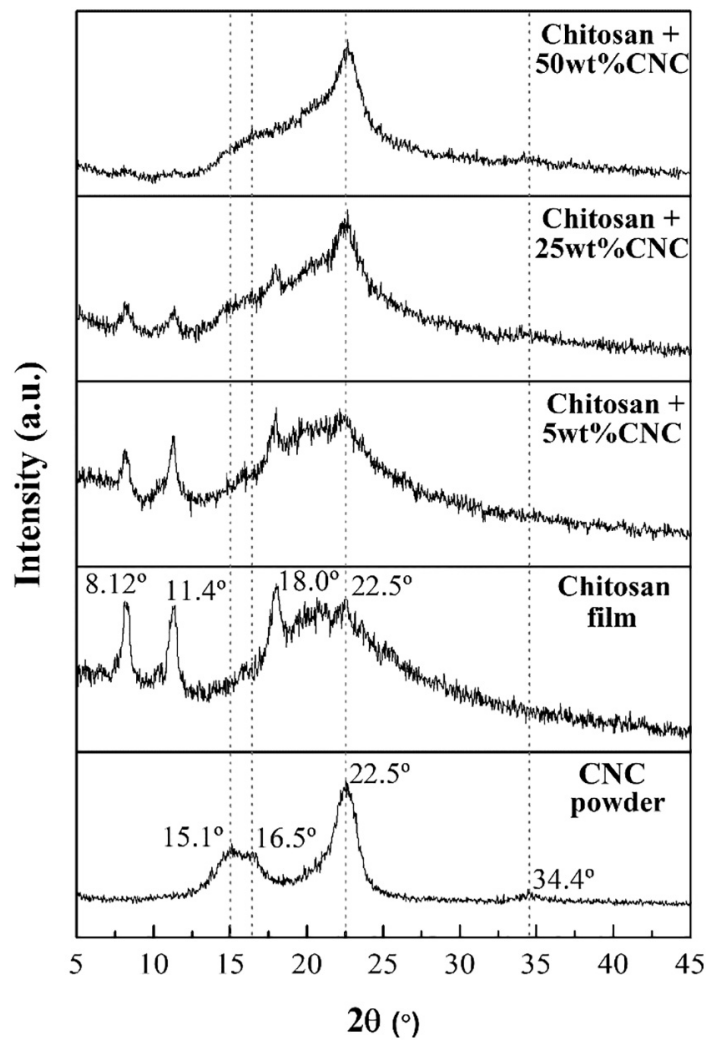

Fig. 5. XRD patterns of CNC powder and chitosan films incorporated with different CNC concentrations $(0,5,25$ and $50 \mathrm{wt} \%)$.
Table 1

Thickness and transparency values of the chitosan films incorporated with different CNC concentrations $(0,5,10,25$ and $50 \mathrm{wt} \%)$.

\begin{tabular}{lll}
\hline Samples & Thickness $(\mathrm{mm})$ & Transparency values (TV) \\
\hline Chitosan film & 0.082 & 0.75 \\
Chitosan+5wt\%CNC & 0.090 & 0.77 \\
Chitosan+10wt\%CNC & 0.094 & 0.79 \\
Chitosan+25wt\%CNC & 0.094 & 1.0 \\
Chitosan+50wt\%CNC & 0.10 & 1.0 \\
\hline
\end{tabular}

values or higher opacity are associated with lower transparency of the films. The transparency values were calculated taking into consideration the transmittance at $600 \mathrm{~nm}$, accordingly with eq. 1 . The obtained results for each sample are shown in Table 1.

An increase in the samples' thickness was observed with the increase of CNC concentration. Regarding transparency, control chitosan films displayed a transparency value of 0.75 , which gradually increased for $0.77,0.79,1.0$ and 1.0 , accordingly with CNC amount, indicating that the incorporation of nanofillers into chitosan promoted a slight decrease in film's transparency. These results can be attributed to the nanofillers accumulation in the polymeric matrix, causing light diffusion or lower light transmittance [18]. Although higher transparency could be preferable since it can directly influence the consumer decision regarding the product, lower transparency can also be a desirable property because the film can act as a barrier to light, protecting the food from degradation [29]. By controlling the CNC amount added to the polymeric formulation, it is possible to obtain films with higher or lower transparency values according with the desirable application: transparency or light barrier. Although the transparency decreases, the developed films still presented enough transparency to see through them.

\subsubsection{Antimicrobial activity}

Food is highly susceptible to spoilage due to microbial attacks during production, processing, and storage. In fact, several bacteria and fungi are responsible for accelerating the food deterioration and may produce a harmful effect on human health [43]. Therefore, novel natural-based strategies are needed to avoid the microorganisms' development in food. To evaluate the potential of the produced films as antimicrobial materials, the antibacterial effect was evaluated against Gram-positive (S. aureus) and Gram-negative (E. coli) bacteria as well as the antifungal activity against $C$. albicans. The results are presented in Table 2.

Chitosan films without CNC showed a bactericidal effect against both S. aureus and E. coli, which means that these samples were able to induce bacteria cell death, instead of only inhibit their growth. Regarding antifungal activity, the chitosan films also presented a fungicidal effect against $C$. albicans. The antimicrobial activity of chitosan has been extensively described in the literature, being the main antimicrobial mechanisms proposed: (i) the electrostatic interaction between positive charges of chitosan with negatively charged microbial cell membranes, leading to the leakage of intracellular constituents and ultimately cell death; (ii) the interaction between chitosan with microbial DNA, affecting the mRNA synthesis and, consequently, the synthesis of proteins; (iii) the chelating properties of chitosan $[3,13,15,44,45]$.

Table 2

Antimicrobial activity of chitosan films incorporated with different $\mathrm{CNC}$ concentrations $(0$ $5,10,25$ and $50 \mathrm{wt} \%$ ).

\begin{tabular}{lllll}
\hline \multirow{2}{*}{ Samples } & \multicolumn{2}{l}{ Antibacterial activity } & & Antifungal activity \\
\cline { 2 - 3 } \cline { 5 - 5 } & S. aureus & E. coli & & C. albicans \\
\hline Chitosan film & $4.57 \pm 0.08$ & $3.54 \pm 1.3$ & & $2.3 \pm 0.27$ \\
Chitosan+5wt\%CNC & $3.7 \pm 1.3$ & $1.89 \pm 0.9$ & & $2.1 \pm 0.04$ \\
Chitosan+10wt\%CNC & Total & Total & & Total \\
Chitosan+25wt\%CNC & Total & Total & & Total \\
Chitosan+50wt\%CNC & $2.9 \pm 0.6$ & Total & & $2.28 \pm 0.1$ \\
\hline
\end{tabular}


Table 3

WVP and $\mathrm{O}_{2} \mathrm{P}$ of chitosan films incorporated with different CNC concentrations $(0,5,10$, 25 and $50 \mathrm{wt} \%$ ). Values are expressed as mean \pm SD. Different letters in the same column correspond to samples statistically different $(p<0.05)$.

\begin{tabular}{lll}
\hline Samples & $\begin{array}{l}\text { WVP x 10 } \\
(\mathrm{g} / \mathrm{m} \mathrm{s} \mathrm{Pa})\end{array}$ & $\begin{array}{l}\mathrm{O}_{2} \mathrm{P} \times 10^{-16} \\
\left(\mathrm{~m}^{3} / \mathrm{s} \mathrm{m} \mathrm{Pa}\right)\end{array}$ \\
\hline Chitosan film & $4.6 \pm 0.65^{\mathrm{ab}}$ & $7.1 \pm 0.76^{\mathrm{a}}$ \\
Chitosan+5wt\%CNC & $4.1 \pm 0.45^{\mathrm{a}}$ & $2.2 \pm 0.28^{\mathrm{bc}}$ \\
Chitosan+25wt\%CNC & $5.3 \pm 0.54^{\mathrm{ac}}$ & $1.6 \pm 0.13^{\mathrm{b}}$ \\
Chitosan+50wt\%CNC & $5.6 \pm 0.51^{\mathrm{bc}}$ & $2.7 \pm 0.63^{\mathrm{c}}$ \\
\hline
\end{tabular}

The bactericidal and the fungicidal effects were maintained after the incorporation of CNC into chitosan films. However, with the incorporation of 10 and $25 \mathrm{wt} \%$ of $\mathrm{CNC}$, the antimicrobial activity is total, showing that these samples are completely bactericidal and fungicidal, which means that they are able to kill all the microorganisms presented in the test. In these cases, it seems to be a synergistic effect between chitosan and CNC. Tyagi et al. [46] hypothesize that when a bacterium encounters rigid, narrow, stiff, rodlike CNC particles, it will undergo significant cell membrane damage. This damaged membrane would make microbial cells susceptible to protonated (cationic) chitosan. Thus, the incorporation of only $10 \%$ of CNC is enough to provides a complete antimicrobial character to these films.

\subsubsection{Barrier properties}

Barrier properties play an important role in food preservation. Limiting the permeation of water vapor and oxygen through the packaging film is essential to prevent microorganism's growth as well as food oxidation, and consequently, food spoilage $[22,47]$. Consequently, to assess the effect of CNC nanofillers into barrier properties of chitosan films, the WVP and $\mathrm{O}_{2} \mathrm{P}$ were evaluated. The results are shown in Table 3.

The WVP of the packaging depends on several aspects such as the composition and hydrophilic-hydrophobic nature of the film, the relation between the crystalline and amorphous zones, and the mobility of the polymeric chains [48]. Additionally, lower WVP values are associated with reduced moisture exchange between the food and the surrounding atmosphere, which is important to prevent or retard food deterioration [8]. Considering the results of WVP, no significant differences between chitosan and chitosan/CNC films were observed, suggesting that $\mathrm{CNC}$ did not affect the affinity of the chitosan films by the water vapor molecules.

On the other hand, oxygen can cause deterioration of packed food altering its color, flavor, or composition; therefore, low values of $\mathrm{O}_{2} \mathrm{P}$ are also preferred. The addition of nanofillers into polymeric matrices can contribute to the reduction of $\mathrm{O}_{2} \mathrm{P}$ values $[16,47]$. Contrary to WVP results, the incorporation of 5,25 and $50 \mathrm{wt} \% \mathrm{CNC}$ led to a significant decrease in $\mathrm{O}_{2} \mathrm{P}\left(2.2 \times 10^{-16}, 1.6 \times 10^{-16}\right.$ and $2.7 \times 10^{-16} \mathrm{~m}^{3} / \mathrm{s} \mathrm{m} \mathrm{Pa}$, respectively) when compared with the $\mathrm{O}_{2} \mathrm{P}$ of the chitosan films $\left(7.1 \times 10^{-16} \mathrm{~m}^{3} / \mathrm{s} \mathrm{m} \mathrm{Pa}\right)$. Several studies have been shown the contribution of CNC to enhance the oxygen barrier properties of different biopolymers, which can be related to the increase in crystallinity, loss of chain mobility and low free volume when nanocellulose is added in the polymeric matrix $[20,49,50]$. Nevertheless, this effect on chitosan films has been poorly explored. Hence, the obtained results confirm the efficacy of these nanofillers to decrease the affinity of the oxygen molecules to the chitosan film, improving the oxygen barrier properties, and consequently, protecting the food from oxidation and spoilage.

\subsubsection{Mechanical properties}

One of the functions of food packaging systems is to protect the food against external environmental conditions. Packaging materials should be able to maintain the food integrity during the processing, handling, and storage processes and, consequently, must exhibit suitable mechanical properties. Nevertheless, biopolymers, like chitosan, display poor mechanical properties comparing to conventional packaging materials. Hence, the addition of nanofillers into polymeric matrices represent a promising approach to improve those properties [16,22]. In order to evaluate the effect of $\mathrm{CNC}$ incorporation into the mechanical properties of chitosan films, tensile tests were performed. The stress-strain curves were determined and the tensile strength, elongation at break, and Young's modulus were calculated for all samples, as demonstrated in Fig. 6.

Chitosan films without CNC presented a tensile strength of $7.98 \mathrm{MPa}$, an elongation at break of $61.4 \%$, and a Young's modulus of $22.4 \mathrm{MPa}$. With the CNC incorporation, a gradual increase in tensile strength to 8.93, 13.0, and 25.3 MPa was observed, accordingly with CNC concentration. However, this difference was only statistically significant with the addition of $50 \mathrm{wt} \% \mathrm{CNC}$. This finding confirmed that with this CNC concentration, chitosan films became stronger and more resistant to stress, which can result from the strong interaction by hydrogen bonds between the nanofillers and matrix. In fact, when the nanofillers are incorporated into polymeric matrices, they can fill the free space between polymer chains, increasing the intermolecular attraction force $[16,23]$. The enhancement in tensile strength of reinforced chitosan films has been reported by several authors $[18,19,22,23,26]$. Xu et al. showed a significant increase in tensile strength of chitosan films from 4.56 to 10.6 MPa, with the incorporation of $5 \%(w / v)$ of CNC, which may arise as a consequence of restricted polymer chain mobility in the vicinity of nanocrystals [22]. Mujtaba et al. developed chitosan films with a tensile strength of $5.4 \mathrm{MPa}$, which improved to 5.86, 5.99, 6.67, and
Tensile Strength (MPa)

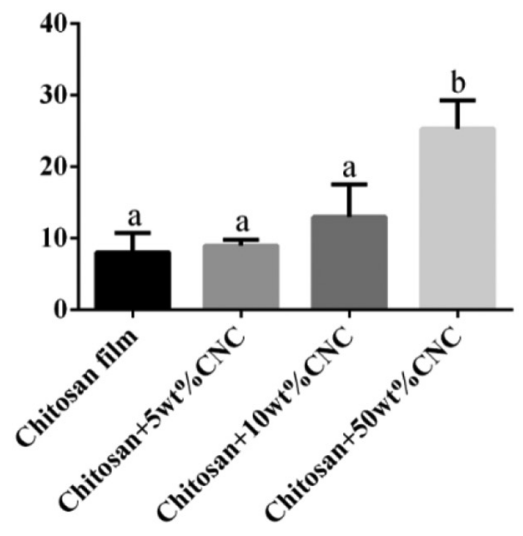

Elongation at Break (\%)

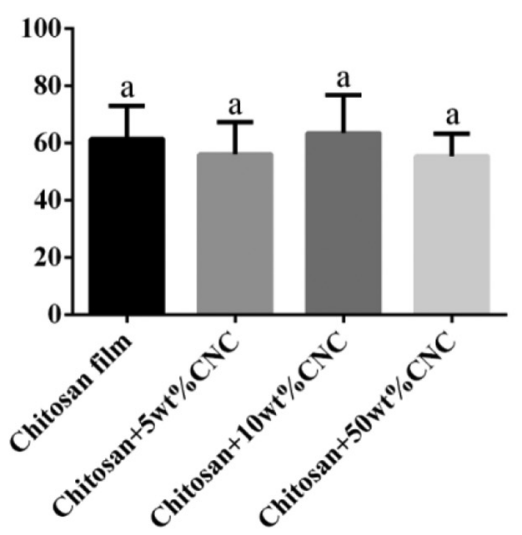

Young's Modulus (MPa)

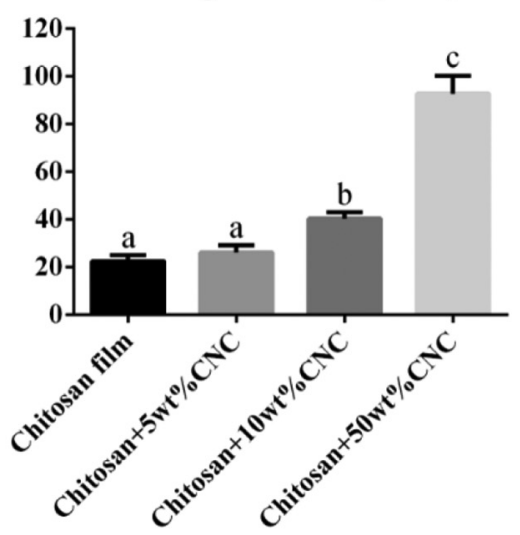

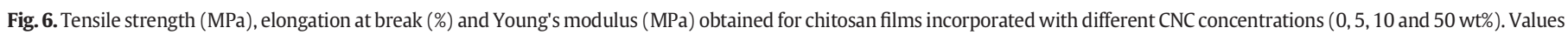
are expressed as mean \pm SD. Different letters in the same graph correspond to samples statistically different $(p<0.05)$. 
6.28 MPa with CNC addition in different amounts (5, 10, 20 and 30\% ( $w /$ w) ) [18]. An enhancement of 5.45, 39.23, 34.84, and $32.45 \%$ was also observed by Yadav et al. in the tensile strength of chitosan films incorporated with CNC [23]. Similar results were also described by Mao et al., who found an increase of $13.2 \%$ in tensile strength with the addition of 3\% CNC [19]. The elongation at break remained relatively unchanged with all the CNC concentrations evaluated, which means that elasticity of the films was not significantly affected with the introduction of the nanofillers.

Young's modulus is also an important parameter to evaluate since it indicates the material's stiffness. An improvement of Young's modulus values was observed with the incorporation of the CNC nanofillers. Chitosan films showed Young's modulus of 22.4 MPa, which increased to 26.1, 40.2, and 92.7 MPa in the presence of 5, 10, and $50 \mathrm{wt} \% \mathrm{CNC}$, respectively. This increase can be ascribed to the improved film's stiffness by the incorporation of $\mathrm{CNC}$, which can be related to its crystalline structure. Similar results were described by previous studies $[18,23,38]$. Overall, these findings showed that CNC act as an excellent reinforcing agent in chitosan films, enhancing their mechanical properties, and demonstrating the potential of these samples to be used in the food packaging industry.

\subsection{Shelf-life tests}

\subsubsection{Microbiological analysis}

Meat is among the most perishable foods since offers a favorable environment for the growth of microorganisms (e.g. high moisture and nutrients), which represents the main contributor to meat spoilage. Hence, retarding the development of microorganisms in food is essential not only to provide higher quality and safety to the consumers, but also to decrease food waste [51]. Thus, in this work, besides only testing the antimicrobial activity of the films, the ability of the samples to act as active packaging membranes in order to decrease the microbial growth in packed food was evaluated using chicken breast during 14 days of storage at $4{ }^{\circ} \mathrm{C}$. Bacteria counts present in the meat packed with different packaging membranes (chitosan, chitosan/50\%CNC and commercial) were performed at specific timepoints, as demonstrated in Fig. 7.

Enterobacteriaceae and Pseudomonas are between the most common bacteria found in fresh meat, thereby contributing to its spoilage [51]. The evaluated bacteria increased throughout the storage time, although their amount was different according to the packaging conditions.

Pseudomonas spp. are generally the predominant bacteria associated with spoilage in aerobically packed meat [52]. The initial population of Pseudomonas spp. presented in chicken meat was $5.7 \log$ CFU/g. Considering that $7 \log \mathrm{CFU} / \mathrm{g}$ of these bacteria is high enough to indicate that meat has been spoiled during storage under refrigerated condition [53], the commercial samples already presented this value after 2 days of storage (Fig. 7A). On the other hand, meat packed with chitosan and chitosan/CNC films showed 2 and $4 \mathrm{log} C F U / g$, respectively.

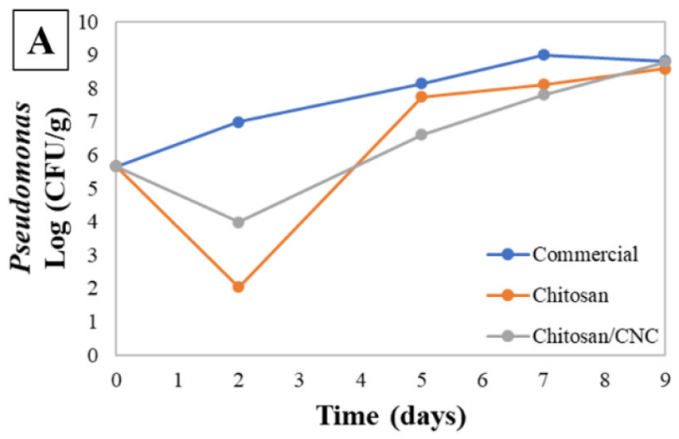

Moreover, during 7 days of storage, the load of Pseudomonas spp. remained higher in meat packed with commercial membranes, showing the ability of the developed samples to preserve meat during the first days of storage. After 9 days of storage, these bacteria showed a very high count, being no differences observed between all samples.

Enterobacteriaceae family are Gram-negative bacteria which includes several foodborne pathogens, such as E. coli, Salmonella, Shigella, among others [54]. The initial population of Enterobacteriaceae was 2.7 $\log$ CFU/g. After 7 days of storage, meat packed with commercial membranes showed an increase to $7.1 \mathrm{log} \mathrm{CFU} / \mathrm{g}$, while meat packed with chitosan and chitosan/CNC films only demonstrated a slight increase to 3.1 and $3.8 \log \mathrm{CFU} / \mathrm{g}$, respectively. At the 9th and 14th days, the amount of Enterobacteriaceae remained lower in meat with chitosan films. Meat packed with chitosan/CNC and commercial films presented identical amount of Enterobacteriaceae at the end of the study.

These results show the efficiency of chitosan-based films in retarding the bacteria growth in meat when compared to commercial membranes, particularly during the first days of storage. These findings can be due to the bactericidal activity demonstrated by chitosan and chitosan/50wt\%CNC films against Gram-negative and Gram-positive bacteria, which was already verified by the results from Table 2. Moreover, the good exudates absorption capacity of the developed samples could also contribute to the delay of microorganism's growth. In fact, the absorption capacity of chitosan, chitosan/CNC and commercial samples was $120 \%, 70 \%$ and $1600 \%$, respectively. Although commercial membranes presented higher values, the absorption capacity of chitosan-based samples was found to be enough for the product in study under testing conditions, since no exudate was found in trays at any time of storage.

Salmonella and L. monocytogenes are considered major foodborne pathogens found in chicken meat and in its processing environment, being a potential source for human illnesses [55]. In fact, Salmonella was not detected in any samples throughout the study, while L. monocytogenes counts were $<1.0 \times 10 \mathrm{CFU} / \mathrm{g}$ for all the analyzed samples. Poultry is also a source and reservoir for Campylobacter spp., which are Gram-negative, microaerophilic and able to grow at temperatures between 37 and $42{ }^{\circ} \mathrm{C}[56,57]$. In the initial meat, Campylobacter spp. were detected with counts of $3.2 \times 10^{3} \mathrm{CFU} / \mathrm{g}$, however, two days later their presence was not observed, being this pattern maintained in all stored samples. Aerobic environments and temperatures below $30{ }^{\circ} \mathrm{C}$ may have contributed to the reduction of Campylobacter during the storage.

\subsubsection{Chemical analysis}

During food storage, several volatile nitrogenous compounds, such as ammonia, trimethylamine and dimethylamine, starting to form due to the degradation of food's nitrogenous compounds by microbial or enzymatic activities. Therefore, the TVB-N index is considered an indicator of spoilage in food [58]. In order to evaluate the potential of chitosan/ CNC films to delay the meat's spoilage, and consequently, extend the

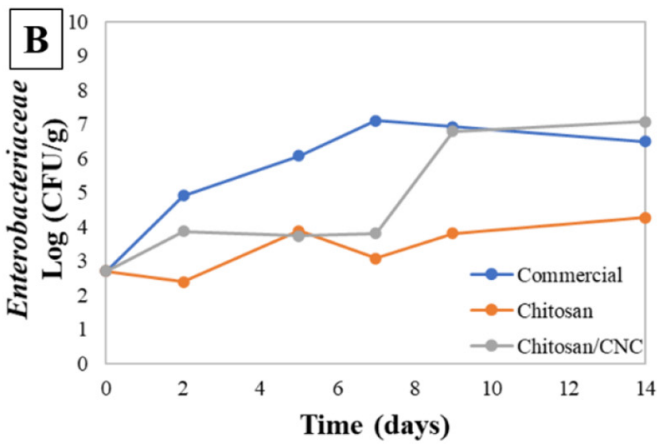

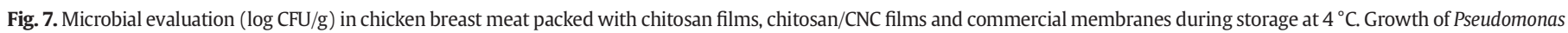
(A) and Enterobacteriaceae (B). 
meat shelf-life, the quantification of TVB-N on meat was also performed at different storage days $(0,2,5,7,9$ and 14$)$ for 14 days at $4{ }^{\circ} \mathrm{C}$. Once again, the evaluation of TVB-N content was carried out in chicken breast meat stored with chitosan, chitosan/50wt\%CNC, and commercial reference membranes. The results are shown in Table 4.

The initial TVB-N amount in chicken breast meat was $10.7 \mathrm{mg} \mathrm{N} /$ $100 \mathrm{~g}$. The TVB-N content seems to increase during storage time for all the samples, which would be expected since meat becomes more susceptible to spoilage over time either by a microbial attack or enzymatic degradation [59]. However, slight differences were observed between the three evaluated samples.

Taking into consideration the results from Table 4, after 2 days of storage, chicken meat stored with chitosan/CNC films showed the highest TVB-N value when compared to chitosan films and commercial membranes. Nevertheless, this value only increased from 15.3 to $18.4 \mathrm{mg} \mathrm{N} / 100 \mathrm{~g}$ until 14 days of storage. The TVB-N content in meat tested with chitosan films displayed more accentuated increase over the storage time, showing TVB-N values of $21.2 \mathrm{mg} \mathrm{N} / 100 \mathrm{~g}$ on the 14 th day. Finally, the chicken meat packed with commercial membranes exhibited the highest increase of TVB-N amount during 14 days of storage, achieving a value of $24.3 \mathrm{mg} \mathrm{N} / 100 \mathrm{~g}$. These results demonstrated the better efficiency of the developed chitosan-based samples in retarding meat's spoilage when compared to commercial membranes.

Since TVB-N can be produced through the degradation of nitrogenous compounds by bacteria, the obtained findings with the chitosanbased samples can be explained by their antibacterial activity against both Gram-negative and Gram-positive bacteria, resulting in lower TVB-N formation [58]. Various studies report that the use of films or edible coatings based only on chitosan or chitosan incorporated with different compounds, including natural extracts and essential oils, could reduce the TVB-N formation in food products under cold conditions $[53,58,60]$.

Moreover, the incorporation of CNC into chitosan films demonstrated greater efficiency in delaying meat deterioration when compared to chitosan films, showing lower values of TVB-N over the storage time. Dehnad et al. demonstrated that chitosan-nanocellulose biocomposites decreased lactic acid bacteria population on the ground meat by approximately 1.3 and 3.1 logarithmic cycles at $3{ }^{\circ} \mathrm{C}$ and $25{ }^{\circ} \mathrm{C}$ compared with nylon packaged samples, respectively, after six days of storage [25].

Therefore, chitosan/CNC films exhibited great potential to preserve meat during storage under refrigerated conditions.

\section{Table 4}

TVB-N content obtained from chicken breast meat packaged with chitosan films, chitosan/ $\mathrm{CNC}$ films and commercial membranes during 14 days of storage at $4{ }^{\circ} \mathrm{C}$. The results are expressed as $\mathrm{mg} \mathrm{N} / 100 \mathrm{~g}$ of chicken breast meat.

\begin{tabular}{|c|c|c|c|}
\hline Storage temperature & Samples & Storage days & $\begin{array}{l}\text { TVB-N } \\
\mathrm{mg} \mathrm{N} / 100 \mathrm{~g}\end{array}$ \\
\hline \multirow{16}{*}{$4{ }^{\circ} \mathrm{C}$} & \multirow{6}{*}{ Chitosan } & 0 & 10.7 \\
\hline & & 2 & 12.2 \\
\hline & & 5 & 15.4 \\
\hline & & 7 & 15.3 \\
\hline & & 9 & 18.4 \\
\hline & & 14 & 21.2 \\
\hline & \multirow{5}{*}{ Chitosan/CNC } & 2 & 15.3 \\
\hline & & 5 & 15.2 \\
\hline & & 7 & 12.3 \\
\hline & & 9 & 15.2 \\
\hline & & 14 & 18.4 \\
\hline & \multirow{5}{*}{ Commercial } & 2 & 10.4 \\
\hline & & 5 & 13.8 \\
\hline & & 7 & 18.4 \\
\hline & & 9 & 21.3 \\
\hline & & 14 & 24.3 \\
\hline
\end{tabular}

\section{Conclusions}

This work shows the development of chitosan/CNC films with enhanced properties to be applied as sustainable alternatives for active food packaging. $\mathrm{CNC}$ addition improved the oxygen barrier, the mechanical properties, and the bactericidal and fungicidal activities of chitosan films, being the incorporation of 10 and $25 \mathrm{wt} \%$ of CNC yielded the highest antimicrobial activity. Additionally, chicken meat packed with both chitosan and chitosan/CNC films showed lower amount of Pseudomonas and Enterobacteriaceae bacteria during the first days of storage at $4{ }^{\circ} \mathrm{C}$, in comparison with commercial membranes. Finally, meat packed with chitosan/CNC systems resulted in the lowest value of TVB-N after 14 days of storage.

\section{CRediT authorship contribution statement}

All authors' individual contributions:

Sofia M. Costa: Investigation; Methodology; Writing - original draft;

Diana P. Ferreira: Conceptualization; Supervision; Validation; Writing - review \& editing.

Pilar Teixeira: Investigation; Methodology; Writing - original draft;

Lina F. Ballesteros: Investigation; Methodology; Writing - original draft;

José A. Teixeira: Supervision; Validation.

Raul Fangueiro: Supervision; Validation.

\section{Acknowledgements}

The authors are thankful to project UID/CTM/00264/2019 of 2C2T Centro de Ciência e Tecnologia Têxtil, funded by National Founds through FCT/MCTES- Fundação para a Ciência e a Tecnologia. Sofia M. Costa is thankful to FCT PhD Scholarship (SFRH/BD/147517/2019). Diana Ferreira is thankful to CEECIND/02803/2017. The authors are also thankful for the financial support of the Portuguese Fundação para a Ciência e a Tecnologia (FCT) under the scope of the strategic funding of UIDB/04469/2020 unit and BioTecNorte operation (NORTE-010145-FEDER-000004) funded by the European Regional Development Fund under the scope of Norte2020 - Programa Operacional Regional do Norte.

\section{References}

[1] S. Yildirim, B. Röcker, M.K. Pettersen, J. Nilsen-Nygaard, Z. Ayhan, R. Rutkaite, T. Radusin, P. Suminska, B. Marcos, V. Coma, Active packaging applications for food, Compr. Rev. Food Sci. Food Saf. 17 (2018) 165-199, https://doi.org/10.1111/15414337.12322.

[2] S. Panseri, P.A. Martino, P. Cagnardi, G. Celano, D. Tedesco, M. Castrica, C. Balzaretti, L.M. Chiesa, Feasibility of biodegradable based packaging used for red meat storage during shelf-life: a pilot study, Food Chem. 249 (2018) 22-29, https://doi.org/10. 1016/j.foodchem.2017.12.067.

[3] N.A. Al-Tayyar, A.M. Youssef, R. Al-hindi, Antimicrobial food packaging based on sustainable bio-based materials for reducing foodborne pathogens: a review, Food Chem. 310 (2020), 125915, https://doi.org/10.1016/j.foodchem.2019.125915.

[4] Y. Zhong, P. Godwin, Y. Jin, H. Xiao, Biodegradable polymers and green-based antimicrobial packaging materials: a mini-review, Adv. Ind. Eng. Polym. Res. 3 (2020) 27-35, https://doi.org/10.1016/j.aiepr.2019.11.002.

[5] E. Kabir, R. Kaur, J. Lee, K.-H. Kim, E.E. Kwon, Prospects of biopolymer technology as an alternative option for non-degradable plastics and sustainable management of plastic wastes, J. Clean. Prod. 258 (2020), 120536, https://doi.org/10.1016/j. jclepro.2020.120536.

[6] D.P. Ferreira, D.S. Conceicao, R.C. Calhelha, T. Sousa, R. Socoteanu, I.C.F.R. Ferreira, L.F. Vieira Ferreira, Porphyrin dye into biopolymeric chitosan films for localized photodynamic therapy of cancer, Carbohydr. Polym. 151 (2016) 160-171, https://doi. org/10.1016/j.carbpol.2016.05.060.

[7] M. Mujtaba, R.E. Morsi, G. Kerch, M.Z. Elsabee, M. Kaya, J. Labidi, K.M. Khawar, Current advancements in chitosan-based film production for food technology; a review, Int. J. Biol. Macromol. 121 (2019) 889-904, https://doi.org/10.1016/j.ijbiomac.2018. 10.109.

[8] A. Riaz, S. Lei, H.M.S. Akhtar, P. Wan, D. Chen, S. Jabbar, M. Abid, M.M. Hashim, X Zeng, Preparation and characterization of chitosan-based antimicrobial active food packaging film incorporated with apple peel polyphenols, Int. J. Biol. Macromol. 114 (2018) 547-555, https://doi.org/10.1016/j.ijbiomac.2018.03.126. 
[9] X. Zhang, J. Liu, H. Yong, Y. Qin, J. Liu, C. Jin, Development of antioxidant and antimicrobial packaging films based on chitosan and mangosteen (Garcinia mangostana L.) rind powder, Int. J. Biol. Macromol. 145 (2020) 1129-1139, https://doi.org/10. 1016/j.ijbiomac.2019.10.038.

[10] K. de la Caba, P. Guerrero, T.S. Trung, M. Cruz-Romero, J.P. Kerry, J. Fluhr, M. Maurer, F. Kruijssen, A. Albalat, S. Bunting, S. Burt, D. Little, R. Newton, From seafood waste to active seafood packaging: an emerging opportunity of the circular economy, J. Clean. Prod. 208 (2019) 86-98, https://doi.org/10.1016/j.jclepro.2018.09.164.

[11] R. Priyadarshi, J.-W. Rhim, Chitosan-based biodegradable functional films for food packaging applications, Innov. Food Sci. Emerg. Technol. 62 (2020), 102346, https://doi.org/10.1016/j.ifset.2020.102346.

[12] S. Kim, Competitive biological activities of chitosan and its derivatives: antimicrobial, antioxidant, anticancer, and anti-inflammatory activities, Int. J. Polym. Sci. 2018 (2018), 1708172, https://doi.org/10.1155/2018/1708172.

[13] A. Riaz, C. Lagnika, H. Luo, Z. Dai, M. Nie, M.M. Hashim, C. Liu, J. Song, D. Li, Chitosanbased biodegradable active food packaging film containing Chinese chive (Allium tuberosum) root extract for food application, Int. J. Biol. Macromol. 150 (2020) 595-604, https://doi.org/10.1016/j.jibiomac.2020.02.078.

[14] H. Wang, J. Qian, F. Ding, Emerging chitosan-based films for food packaging applications, J. Agric. Food Chem. 66 (2018) 395-413, https://doi.org/10.1021/acs.jafc. $7 \mathrm{~b} 04528$.

[15] D. MubarakAli, F. LewisOscar, V. Gopinath, N.S. Alharbi, S.A. Alharbi, N. Thajuddin, An inhibitory action of chitosan nanoparticles against pathogenic bacteria and fungi and their potential applications as biocompatible antioxidants, Microb. Pathog. 114 (2018) 323-327, https://doi.org/10.1016/j.micpath.2017.11.043.

[16] E. Jamroz, P. Kulawik, P. Kopel, The effect of nanofillers on the functional properties of biopolymer-based films: a review, Polymers (Basel) 11 (2019) 675, https://doi. org/10.3390/polym11040675.

[17] V.G.L. Souza, J.R.A. Pires, C. Rodrigues, I.M. Coelhoso, A.L. Fernando, Chitosan composites in packaging industry-current trends and future challenges, Polymers (Basel) 12 (2020) 417, https://doi.org/10.3390/polym12020417.

[18] M. Mujtaba, A.M. Salaberria, M.A. Andres, M. Kaya, A. Gunyakti, J. Labidi, Utilization of flax (Linum usitatissimum) cellulose nanocrystals as reinforcing material for chitosan films, Int. J. Biol. Macromol. 104 (2017) 944-952, https://doi.org/10.1016/j. ijbiomac.2017.06.127.

[19] H. Mao, C. Wei, Y. Gong, S. Wang, W. Ding, Mechanical and water-resistant properties of eco-friendly chitosan membrane reinforced with cellulose nanocrystals, Polymers (Basel) 11 (2019) 166, https://doi.org/10.3390/polym11010166.

[20] P. Criado, C. Fraschini, F. Hossain, M. Lacroix, Cellulose Nanocrystals in food packaging, in: G. Smithers, V. Trinetta, K. Knoerzer (Eds.), Reference Module in Food Science, Elsevier, 2019.

[21] M. Hubbe, A. Ferrer, P. Tyagi, Y. Yin, C. Salas, L. Pal, O. Rojas, Nanocellulose in thin films, coatings, and plies for packaging applications: a review, BioResources 12 (2017) 2143-2233, https://doi.org/10.15376/biores.12.1.2143-2233.

[22] Y. Xu, S. Willis, K. Jordan, E. Sismour, Chitosan nanocomposite films incorporating cellulose nanocrystals and grape pomace extracts, Packag. Technol. Sci. 31 (2018) 631-638, https://doi.org/10.1002/pts.2389.

[23] M. Yadav, K. Behera, Y.-H. Chang, F.-C. Chiu, Cellulose nanocrystal reinforced chitosan based UV barrier composite films for sustainable packaging, Polymers (Basel) 12 (2020) 202, https://doi.org/10.3390/polym12010202.

[24] M.R. de Andrade, T.B.R. Nery, T.I. de Santana, E. Santana, I.L. Leal, L.A.P. Rodrigues, J.H. de Oliveira Reis, J.I. Druzian, B.A.S. Machado, Effect of cellulose nanocrystals from different lignocellulosic residues to chitosan/glycerol films, Polymers (Basel) 11 (2019) 658, https://doi.org/10.3390/polym11040658.

[25] D. Dehnad, H. Mirzaei, Z. Emam-Djomeh, S.-M. Jafari, S. Dadashi, Thermal and antimicrobial properties of chitosan-nanocellulose films for extending shelf life of ground meat, Carbohydr. Polym. 109 (2014) 148-154, https://doi.org/10.1016/j. carbpol.2014.03.063.

[26] A. Khan, R.A. Khan, S. Salmieri, C. Le Tien, B. Riedl, J. Bouchard, G. Chauve, V. Tan, M.R Kamal, M. Lacroix, Mechanical and barrier properties of nanocrystalline cellulose reinforced chitosan based nanocomposite films, Carbohydr. Polym. 90 (2012) 1601-1608, https://doi.org/10.1016/j.carbpol.2012.07.037.

[27] Y.A. Arfat, J. Ahmed, M. Ejaz, M. Mullah, Polylactide/graphene oxide nanosheets/ clove essential oil composite films for potential food packaging applications, Int. J. Biol. Macromol. 107 (2018) 194-203, https://doi.org/10.1016/j.ijbiomac.2017.08. 156.

[28] C. Fernandes, S. Calderon V, L.F. Ballesteros, M.A. Cerqueira, L.M. Pastrana, J.A. Teixeira, P.J. Ferreira, S. Carvalho, Carbon-based sputtered coatings for enhanced chitosan-based films properties, Appl. Surf. Sci. 433 (2018) 689-695, https://doi. org/10.1016/j.apsusc.2017.10.088.

[29] L.F. Ballesteros, M.A. Cerqueira, J.A. Teixeira, S.I. Mussatto, Production and physicochemical properties of carboxymethyl cellulose films enriched with spent coffee grounds polysaccharides, Int. J. Biol. Macromol. 106 (2018) 647-655, https://doi. org/10.1016/j.ijbiomac.2017.08.060.

[30] A.S. Ferreira, C. Nunes, A. Castro, P. Ferreira, M.A. Coimbra, Influence of grape pomace extract incorporation on chitosan films properties, Carbohydr. Polym. 113 (2014) 490-499, https://doi.org/10.1016/j.carbpol.2014.07.032.

[31] H. Kargarzadeh, R.M. Sheltami, I. Ahmad, I. Abdullah, A. Dufresne, Cellulose nanocrystal: a promising toughening agent for unsaturated polyester nanocomposite, Polymer (Guildf) 56 (2015) 346-357, https://doi.org/10.1016/j.polymer.2014.11. 054.

[32] M.G. Aguayo, A. Fernandez Perez, G. Reyes, C. Oviedo, W. Gacitua, R. Gonzalez, O. Uyarte, Isolation and characterization of cellulose nanocrystals from rejected fibers originated in the kraft pulping process, Polymers (Basel) 10 (2018) 1145, https:// doi.org/10.3390/polym10101145.
[33] H. Celebi, A. Kurt, Effects of processing on the properties of chitosan/cellulose nanocrystal films, Carbohydr. Polym. 133 (2015) 284-293, https://doi.org/10.1016/j. carbpol.2015.07.007.

[34] Q.-J. Chen, L.-L. Zhou, J.-Q. Zou, X. Gao, The preparation and characterization of nanocomposite film reinforced by modified cellulose nanocrystals, Int. J. Biol. Macromol. 132 (2019) 1155-1162, https://doi.org/10.1016/j.ijbiomac.2019.04.063.

[35] L. Amoroso, G. Muratore, M.A. Ortenzi, S. Gazzotti, S. Limbo, L. Piergiovanni, Fast production of cellulose nanocrystals by hydrolytic-oxidative microwave-assisted treatment, Polymers (Basel) 12 (2020) 68, https://doi.org/10.3390/polym12010068.

[36] M. Salari, M. Sowti Khiabani, R. Rezaei Mokarram, B. Ghanbarzadeh, H. Samadi Kafil, Development and evaluation of chitosan based active nanocomposite films containing bacterial cellulose nanocrystals and silver nanoparticles, Food Hydrocoll. 84 (2018) 414-423, https://doi.org/10.1016/j.foodhyd.2018.05.037.

[37] M. Kaya, S. Khadem, Y.S. Cakmak, M. Mujtaba, S. Ilk, L. Akyuz, A.M. Salaberria, J. Labidi, A.H. Abdulqadir, E. Deligöz, Antioxidative and antimicrobial edible chitosan films blended with stem, leaf and seed extracts of Pistacia terebinthus for active food packaging, RSC Adv. 8 (2018) 3941-3950, https://doi.org/10.1039/ C7RA12070B.

[38] Y. Tang, X. Zhang, R. Zhao, D. Guo, J. Zhang, Preparation and properties of chitosan/ guar gum/nanocrystalline cellulose nanocomposite films, Carbohydr. Polym. 197 (2018) 128-136, https://doi.org/10.1016/j.carbpol.2018.05.073.

[39] C.F. Bellani, E. Pollet, A. Hebraud, F.V. Pereira, G. Schlatter, L. Avérous, R.E.S. Bretas, M.C. Branciforti, Morphological, thermal, and mechanical properties of poly $(\varepsilon-$ caprolactone $) / \operatorname{poly}(\varepsilon$-caprolactone)-grafted-cellulose nanocrystals mats produced by electrospinning, J. Appl. Polym. Sci. 133 (2016) 43445, https://doi.org/10.1002/ app.43445.

[40] J. Gong, J. Li, J. Xu, Z. Xiang, L. Mo, Research on cellulose nanocrystals produced from cellulose sources with various polymorphs, RSC Adv. 7 (2017) 33486-33493, https://doi.org/10.1039/C7RA06222B.

[41] F.A. Corsello, P.A. Bolla, P.S. Anbinder, M.A. Serradell, J.I. Amalvy, P.J. Peruzzo, Morphology and properties of neutralized chitosan-cellulose nanocrystals biocomposite films, Carbohydr. Polym. 156 (2017) 452-459, https://doi.org/10.1016/j.carbpol. 2016.09.031.

[42] Q. Xu, Y. Ji, Q. Sun, Y. Fu, Y. Xu, L. Jin, Fabrication of cellulose nanocrystal/chitosan hydrogel for controlled drug release, Nanomater. (Basel, Switzerland). 9 (2019) 253, https://doi.org/10.3390/nano9020253.

[43] T. Martinović, U. Andjelković, M.Š. Gajdošik, D. Rešetar, D. Josić, Foodborne pathogens and their toxins, J. Proteome 147 (2016) 226-235, https://doi.org/10.1016/j. jprot.2016.04.029.

[44] A.G. Inanli, E.T.A. Tümerkan, N. El Abed, J.M. Regenstein, F. Özogul, The impact of chitosan on seafood quality and human health: a review, Trends Food Sci. Technol. 97 (2020) 404-416, https://doi.org/10.1016/j.tifs.2020.01.029.

[45] S. Kumar, A. Mukherjee, J. Dutta, Chitosan based nanocomposite films and coatings: emerging antimicrobial food packaging alternatives, Trends Food Sci. Technol. 97 (2020) 196-209, https://doi.org/10.1016/j.tifs.2020.01.002.

[46] P. Tyagi, R. Mathew, C. Opperman, H. Jameel, R. Gonzalez, L. Lucia, M. Hubbe, L. Pal, High-strength antibacterial chitosan-cellulose nanocrystal composite tissue paper, Langmuir 35 (2019) 104-112, https://doi.org/10.1021/acs.langmuir.8b02655.

[47] A. Dey, S. Neogi, Oxygen scavengers for food packaging applications: a review, Trends Food Sci. Technol. 90 (2019) 26-34, https://doi.org/10.1016/j.tifs.2019.05. 013.

[48] B. Souza, M. Cerqueira, J. Teixeira, A. Vicente, The use of electric fields for edible coatings and films development and production: a review, Food Eng. Rev. 2 (2010) 244-255, https://doi.org/10.1007/s12393-010-9029-X.

[49] F. Vilarinho, A. Sanches Silva, M.F. Vaz, J.P. Farinha, Nanocellulose in green food packaging, Crit. Rev. Food Sci. Nutr. 58 (2018) 1526-1537, https://doi.org/10. 1080/10408398.2016.1270254

[50] P. Criado, C. Fraschini, S. Salmieri, M. Lacroix, Cellulose nanocrystals (CNCs) loaded alginate films against lipid oxidation of chicken breast, Food Res. Int. 132 (2020), 109110, https://doi.org/10.1016/j.foodres.2020.109110.

[51] O.A. Odeyemi, O.O. Alegbeleye, M. Strateva, D. Stratev, Understanding spoilage microbial community and spoilage mechanisms in foods of animal origin, Compr. Rev. Food Sci. Food Saf. 19 (2020) 311-331, https://doi.org/10.1111/1541-4337. 12526.

[52] A.J. Pellissery, P.G. Vinayamohan, M.A.R. Amalaradjou, K. Venkitanarayanan, Chapter 17 - spoilage bacteria and meat quality, in: A.K. Biswas, P.K. Mandal (Eds.), Meat Quality Analysis, Academic Press 2020, pp. 307-334.

[53] A. Khezrian, Y. Shahbazi, Application of nanocompostie chitosan and carboxymethyl cellulose films containing natural preservative compounds in minced camel's meat, Int. J. Biol. Macromol. 106 (2018) 1146-1158, https://doi.org/10.1016/j.ijbiomac. 2017.08.117.

[54] J.L. Smith, P. Fratamico, Escherichia coli and other Enterobacteriaceae: food poisoning and health effects, in: B. Caballero, P.M. Finglas, F. Toldrá (Eds.), Encyclopedia of Food and Health, Academic Press 2016, pp. 539-544.

[55] M. Abatcha, Salmonella and listeria monocytogenes: a review of prevalence and antibiotic resistance in chickens and their processing environments, Adv. Anim. Vet. Sci. 5 (2017) 395, https://doi.org/10.17582/journal.aavs/2017/5.9.395.403.

[56] C.P.A. Skarp, M.-L. Hänninen, H.I.K. Rautelin, Campylobacteriosis: the role of poultry meat, Clin. Microbiol. Infect. 22 (2016) 103-109, https://doi.org/10.1016/j.cmi.2015. 11.019.

[57] J. Silva, D. Leite, M. Fernandes, C. Mena, P.A. Gibbs, P. Teixeira, Campylobacter spp. as a foodborne pathogen: a review, Front. Microbiol. 2 (2011) 200, https://doi.org/10. 3389/fmicb.2011.00200.

[58] S. Shokri, K. Parastouei, M. Taghdir, S. Abbaszadeh, Application an edible active coating based on chitosan- Ferulago angulata essential oil nanoemulsion to shelf life 
extension of rainbow trout fillets stored at 4 degrees C, Int. J. Biol. Macromol. 153 (2020) 846-854, https://doi.org/10.1016/j.jibiomac.2020.03.080.

[59] A. Duran, H.I. Kahve, The effect of chitosan coating and vacuum packaging on the microbiological and chemical properties of beef, Meat Sci. 162 (2020), 107961, https://doi.org/10.1016/j.meatsci.2019.107961.
[60] T. Mehdizadeh, A. Mojaddar Langroodi, Chitosan coatings incorporated with propolis extract and Zataria multiflora Boiss oil for active packaging of chicken breast meat, Int. J. Biol. Macromol. 141 (2019) 401-409, https://doi.org/10.1016/j. ijbiomac.2019.08.267. 